\title{
Birthweight and Environmental Conditions Impact Skin Barrier Adaptation in Neonates Receiving Natural Oil Massage
}

\author{
Marty O. Visscher ${ }^{a} \quad$ Aimee Summers ${ }^{b}$ Vivek Narendran ${ }^{a}$ Subarna Khatry ${ }^{c}$ \\ Jeevan Sherchand ${ }^{d}$ Steven LeClerq $^{\text {b, c }}$ Joanne Katz ${ }^{b}$ James Tielsch $^{\mathrm{e}}$ \\ Luke Mullanyb \\ ${ }^{a}$ Cincinnati Children's Hospital Medical Center, Cincinnati, OH, USA; ${ }^{b}$ Department of International Health, Johns \\ Hopkins Bloomberg School of Public Health, Baltimore, MD, USA; ${ }^{C}$ Nepal Nutrition Intervention Project-Sarlahi \\ (NNIPS), Kathmandu, Nepal; ${ }^{d}$ Department of Microbiology, Institute of Medicine, Tribhuvan University Teaching

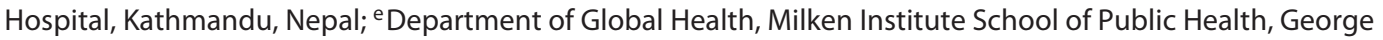 \\ Washington University, Washington, DC, USA
}

\section{Keywords}

Skin barrier · Skin integrity · Stratum corneum · Infant · Neonate $\cdot$ Premature infant $\cdot$ Skin $\mathrm{pH} \cdot$ Transepidermal water loss · Topical natural oil · Massage · Environmental conditions

\footnotetext{
Abstract

Introduction: Skin interventions have been implemented to reduce neonatal mortality, demonstrating the skin's role in neonatal innate immunity. We examined the impact of birthweight and environmental conditions on skin integrity in infants receiving oil massage in rural Nepal. Methods: In a community-based cluster randomized controlled trial, 991 premature and full-term infants were grouped by birthweight as: (1) 920-1,560 g, (2) 1,570-2,450 g, (3) 2,4602,990 $\mathrm{g}$, and (4) 3,000-4,050 $\mathrm{g}$ and by high or low heat index (HI). Skin integrity was measured as erythema, rash, dryness, $\mathrm{pH}$, protein concentration, and transepidermal water loss (TEWL). Results: Skin pH was higher for the smallest (group 1) than the largest infants (group 4) and higher for group 2 than 3 and 4 . Arm and leg rash differed for all 4 groups, with
}

karger@karger.com
www.karger.com/bmh
Karger $\%$
马OPEN ACCESS

C 2021 The Author(s)

Published by S. Karger AG, Basel

This is an Open Access article licensed under the Creative Commons Attribution-NonCommercial-4.0 International License (CC BY-NC) (http://www.karger.com/Services/OpenAccessLicense), applicable to the online version of the article only. Usage and distribution for commercial purposes requires written permission. the least amount of rash for the smallest babies. Erythema was lower for group 1 than all others. The lower day 1 values for $\mathrm{pH}$, TEWL and protein at high versus low $\mathrm{HI}$ remained lower over 28 days. The $\mathrm{pH}$ reduction was faster at high $\mathrm{HI}$. Erythema (arm, leg) was more severe at high HI. Rash severity was greater at high $\mathrm{HI}$ for arms and legs every day. Conclusions: Birthweight influenced the skin response to oil massage. The smallest infants had the lowermost skin irritation, suggesting diminished ability to mount an inflammatory response. High $\mathrm{HI}$ may be protective for premature infants in low resource settings.

(C) 2021 The Author(s)

Published by S. Karger AG, Basel

\section{Introduction}

Identification of efficacious interventions to reduce neonatal mortality in low income settings has demonstrated the critical role of neonatal skin to provide robust innate immunity via antimicrobial and physical barriers. Interventions include kangaroo mother care, umbilical cord cleansing with chlorhexidine, and topical emollient 
application. Environmental conditions, skin care practices, and demographics, for example, gestational age (GA), are among the factors that may impact skin adaptation after birth. An improved understanding of these effects is critical to the delivery of optimum interventions in community and hospital settings.

Based on infection risk reduction and improved skin condition from topical sunflower seed oil (SSO) in premature infants [1], we extended the work to a broader population-based sample (all babies, regardless of GA) in rural Nepal, where mustard oil (MO) is widely used for daily massage [2]. We quantified skin integrity among 995 infants receiving SSO or MO nested within a larger cluster-randomized trial and found a more rapid $\mathrm{pH}$ reduction with SSO [3].

Premature birth, along with rising costs, is a significant global health issue regardless of region and healthcare availability [4]. Developing countries report $98 \%$ of global neonatal deaths [5], with 50\% from infections [6]. Neonatal skin provides innate immunity. The skin barrier is underdeveloped in preterms, increasing infection risk and permeability to exogenous irritants [7]. Global skin care goals are to facilitate development and maintenance of a robust barrier. This report aimed to understand the impact of birthweight and environmental conditions (HI) on skin integrity over postnatal month 1 . Infants were categorized by birthweight, since GA estimation by last menstrual period is less exact than others, for example, ultrasound [8]. From 991 birthweights, 4 groups were assigned a priori as: group (1) 920-1,560 g, group (2) $1,570-2,450$ g, group (3) $2,460-2,990 \mathrm{~g}$, and group (4) $3,000-4,050 \mathrm{~g}$, representing approximate GAs of 26-31, $31-35,35-37$ and $>37$ weeks, respectively, based on normative 50th percentile weights [9]. This allowed comparison of the smallest infants to heavier babies. Nearly half of the infants were 2,460-2,990 $\mathrm{g}$ at birth.

\section{Materials and Methods}

\section{Setting and Parent Trial}

Data for this report originated from a cluster-randomized studynested within alarger trial (ClinicalTrials.gov,NCT01177111) of topical skin emollient effects on newborn mortality and morbidity in the community setting in Sarlahi District, Nepal. Pregnant women were enrolled at home visits and followed through delivery. Visits occurred after birth (day 1) and on days 3, 7, 10, 14, 21 and 28 . The 34 village development communities were divided into sectors and randomized to full-body topical applications via routine massage of either SSO or MO. Restricted randomization was conducted in sectors with prior neonatal death to ensure the balance on mortality risk.

\section{Skin Barrier Maturation Study}

The nested study enrolled a subset including all preterm and a randomly selected $20 \%$ sample of full-term infants before $48 \mathrm{~h}$ of age between July 2012 and May 2014 [3]. After obtaining informed consent from mothers for infant participation, specialized field staff conducted study measurements. The Ethical Review Committee of the Institute of Medicine, Tribhuvan University (Kathmandu, Nepal) and the Institutional Review Board of the Johns Hopkins Bloomberg School of Public Health approved the study.

\section{Measurements}

Infants were weighed on day 1 (BD-585 Pediatric Scale [10 g precision]; Tanita Corporation of America, Arlington Heights, IL, USA). Skin integrity was evaluated on days $1,3,7,14$ and 28 for erythema (0-3), rash (0-3) and dryness (0-5; chest, arms, legs) with 0 as no visual compromise and 3 or 5 indicating greater damage [10]. Visible erythema is an indicator of inflammation, that is, abnormal redness from capillary dilation and increased blood flow. It is initially diffuse and may progress to excoriation or loss of skin surface layers. Rash refers to discrete areas of irritation, that is, papules, that may be around the hair follicle or the eccrine gland opening. Instrumental measures of skin pH (chest, SkinCheck; Hanna Instruments, Bedfordshire, UK), TEWL $\left(\mathrm{g} / \mathrm{m}^{2} / \mathrm{h}\right.$, chest, closed-chamber VapoMeter; Delfin Technologies, Kuopio, Finland, VapoMeter; Delfin Technologies, Kuopio, Finland), protein (stratum corneum cohesion via surface sample collection with $380 \mathrm{~mm}^{2} \mathrm{D}$-squame discs; CuDerm, Dallas, TX, USA), heat index (HI), temperature, and humidity were recorded [11]. HI considers both air temperature and relative humidity. The equation is as follows where $\mathrm{T}$ is ambient dry bulb temperature in degrees Fahrenheit and $\mathrm{R}$ is relative humidity in integer percentage [12]:

$$
\begin{aligned}
& \mathrm{HI}=-42.379+2.04901523 \mathrm{~T}+10.14333127 \mathrm{R}- \\
& 0.22475541 \mathrm{TR}-6.83783 \times 10^{-3} \mathrm{~T}^{2}- \\
& 5.481717 \times 10^{-2} \mathrm{R}^{2}+1.22874 \times 10^{-3} \mathrm{~T}^{2} \mathrm{R}+8.5282 \times 10^{-4} \mathrm{TR}^{2}- \\
& 1.99 \times 10^{-6} \mathrm{~T}^{2} \mathrm{R}^{2}
\end{aligned}
$$

Protein was quantified as optical density (SquameScan 850A; Heiland electronic, Wetzlar, Germany).

\section{Infant Classification}

Infants were segmented into 4 birthweight groups and to one of 2 groups based on low or high HI, defined as below or above the mean (and median) of $34.0^{\circ} \mathrm{C}$.

\section{Statistical Analyses}

Infant characteristics, baseline measures and changes were evaluated with general linear models (GLM; SPSS version 24, SPSS, Inc., Chicago, IL, USA), significance was set at $p \leq 0.05$. Effects over time were assessed using linear mixed models repeated measures procedures ( $F$ statistic, $p \leq 0.05$ ). Covariates were baseline skin value, treatment, GA, birthweight and number of massages per $24 \mathrm{~h}$. The linear mixed models procedure permits analysis of subjects measured at different times, inclusion of incomplete cases and where the effects at any given day are influenced by previous treatments [13]. The impact of $\mathrm{HI}$ on $\mathrm{pH}$ change rate was determined from individual slopes.
Visscher et al. 
Table 1. Subject demographics and environmental conditions as mean, SEM and range

\begin{tabular}{|c|c|c|c|c|c|c|}
\hline & $\begin{array}{l}\text { Total } \\
\text { population }\end{array}$ & Group 1 & Group 2 & Group 3 & Group 4 & $\begin{array}{l}\text { Statistics and post hoc } \\
\text { comparisons }^{\dagger}\end{array}$ \\
\hline Unique subjects & 991 & 25 & 301 & 466 & 199 & \\
\hline Birthweight, g & $\begin{array}{l}2,615 \pm 468 \\
(920-4,050)\end{array}$ & $\begin{array}{l}1,353 \pm 165 \\
(920-1,560)\end{array}$ & $\begin{array}{l}2,165 \pm 220 \\
(1,570-2,450)\end{array}$ & $\begin{array}{l}2,708 \pm 148 \\
(2,460-2,990)\end{array}$ & $\begin{array}{l}3,237 \pm 219 \\
(3,000-4,050)\end{array}$ & $\begin{array}{l}F=1,717, p<0.001 \\
\text { All groups }-S \text { - than each other }\end{array}$ \\
\hline Gestational age, weeks & $\begin{array}{l}37.9 \pm 3.6 \\
(22.6-49.4)\end{array}$ & $\begin{array}{l}33.5 \pm 3.0 \\
(26.1-39.9)\end{array}$ & $\begin{array}{l}37.2 \pm 3.5 \\
(23.2-49.4)\end{array}$ & $\begin{array}{l}38.3 \pm 3.5 \\
(22.6-48.7)\end{array}$ & $\begin{array}{l}38.7 \pm 3.2 \\
(25.4-46.6)\end{array}$ & $\begin{array}{l}F=23.6, p<0.001 \\
\text { Groups } 1,2-S \text { - lower than groups } \\
3,4\end{array}$ \\
\hline Heat index, ${ }^{\circ} \mathrm{C}$ & $\begin{array}{l}34.0 \pm 9.1 \\
(13.9-55.8)\end{array}$ & $\begin{array}{l}34.5 \pm 7.2 \\
(24.7-49.2)\end{array}$ & $\begin{array}{l}34.0 \pm 9.3 \\
(14.2-55.2)\end{array}$ & $\begin{array}{l}34.2 \pm 9.1 \\
(13.9-55.8)\end{array}$ & $\begin{array}{l}33.4 \pm 8.9 \\
(14.2-53.4)\end{array}$ & $F=0.33, p=0.80$ \\
\hline Relative humidity (\%RH) & $\begin{array}{l}74.9 \pm 13.3 \\
(10-99)\end{array}$ & $\begin{array}{l}72.0 \pm 12.9 \\
(52-96)\end{array}$ & $\begin{array}{l}75.6 \pm 13.9 \\
(10-99)\end{array}$ & $\begin{array}{l}74.9 \pm 13.3 \\
(30-99)\end{array}$ & $\begin{array}{l}74.2 \pm 12.8 \\
(39-98)\end{array}$ & $F=0.80, p=0.49$ \\
\hline Temperature & $\begin{array}{l}28.2 \pm 4.3 \\
(15-36)\end{array}$ & $\begin{array}{l}29.0 \pm 2.4 \\
(24-33)\end{array}$ & $\begin{array}{l}28.2 \pm 4.4 \\
(15-35)\end{array}$ & $\begin{array}{l}28.4 \pm 4.4 \\
(15-36)\end{array}$ & $\begin{array}{l}27.9 \pm 4.6 \\
(13-35)\end{array}$ & $F=0.41, p=0.75$ \\
\hline Number of massages in $24 \mathrm{~h}$ & $\begin{array}{l}3.4 \pm 20 \\
(1-14)\end{array}$ & $\begin{array}{l}4.2 \pm 2.9 \\
(1-12)\end{array}$ & $\begin{array}{l}3.7 \pm 2.1 \\
(1-14)\end{array}$ & $\begin{array}{l}3.3 \pm 1.8 \\
(1-12)\end{array}$ & $\begin{array}{l}3.0 \pm 1.9 \\
(1-12)\end{array}$ & $\begin{array}{l}F=6.02, p<0.001 \\
\text { Groups } 1,2 \text {-S- higher than group } \\
4\end{array}$ \\
\hline Females/males & $\begin{array}{l}464 / 527^{*} \\
p=0.005\end{array}$ & $\begin{array}{l}14 / 11 \\
p=0.40\end{array}$ & $\begin{array}{l}166 / 135^{*} \\
p=0.011\end{array}$ & $\begin{array}{l}212 / 254^{*} \\
p=0.006\end{array}$ & $\begin{array}{l}72 / 127^{*} \\
p<0.001\end{array}$ & $p<0.05$ \\
\hline Mustard oil/sunflower oil & $\begin{array}{l}496 / 495 \\
p=0.97\end{array}$ & $\begin{array}{l}7 / 18^{* *} \\
p=0.002\end{array}$ & $\begin{array}{l}137 / 164^{* *} \\
p=0.028\end{array}$ & $\begin{array}{l}251 / 215^{* *} \\
p=0.018\end{array}$ & $\begin{array}{l}101 / 98 \\
p=0.76\end{array}$ & $p<0.05$ \\
\hline
\end{tabular}

${ }^{\dagger}$ Post hoc pairwise comparisons from statistically significant general linear model results $(p<0.05)$. S indicates the post hoc pairwise comparisons that were significant $(p<0.05)$. * Indicates gender difference. ${ }^{* *}$ Indicates treatment difference.

\section{Results}

\section{Birthweight Group and Skin Integrity}

Mean birthweights ( $n=991)$ were: (1) $1,353 \pm 38 \mathrm{~g}$, (2) $2,165 \pm 11 \mathrm{~g}$, (3) $2,708 \pm 9 \mathrm{~g}$, and (4) $3,237 \pm 13 \mathrm{~g}(p<0.05$; Table 1). GA was lower for groups 1 and 2 and comparable for 3 and 4 (Table 1). Day 1 HIs, relative humidity and temperatures did not differ. The smallest babies (groups 1 and 2) were massaged more often than the largest infants $(p<0.05$; Table 1$)$. Male subjects were overrepresented in all birthweight groups except group 1 . The skin integrity measurements did not vary by infant gender in this neonatal population (data not shown). Infants massaged with SSO were overrepresented in groups 1 and 2 and those receiving MO were higher in group 3. Separate analyses of each birthweight group indicated no differences in outcome measures for MO versus SSO (data not shown). However, treatment was included as a covariate in the statistical analyses due to differences in representation.

Baseline $\mathrm{pH}$, TEWL, protein, erythema (all sites) and rash (arm) did not differ by birthweight (online suppl. Table S1; for all online suppl. material, see www.karger. com/doi/10.1159/000512274). Over 28 days, $\mathrm{pH}$ was higher for the smallest than the largest infants and higher for group 2 than 3 and 4 ( $p<0.05$; Fig. 1a). Arm and leg rash severities differed for all groups $(p<0.05)$. The smallest infants had the lowest rash (Fig. 1b; online suppl. Table S2). Chest rash was lower for groups 1 and 2 than all others ( $p<0.05$; online suppl. Table S2). Erythema was lower for group 1 than all others $(p<0.05$; Fig. $1 c$, online suppl. Table S2). Arm dryness was low, varying over time for groups 2, 3 and 4, increasing to significance on day 7 (group 2) and day 14 (groups 3,4 ) before decreasing by day $28(p<0.05$; Table 2$)$.

\section{HI and Skin Integrity}

Baseline HIs (968 infants) were $26.3 \pm 0.2$ and $41.7 \pm$ $0.2^{\circ} \mathrm{C}$ for low and high HIs, respectively (Table 3 ). Birthweight, GA and massages per $24 \mathrm{~h}$ were comparable.

Baseline $\mathrm{pH}, \mathrm{TEWL}$, protein and chest erythema scores were lower (less severe) at high versus low $\mathrm{HI}(p<0.05$; online suppl. Table S3). Arm and leg rash were higher at high HI ( $p<0.05$; online suppl. Table S3). The lower $\mathrm{pH}$, TEWL and protein on day 1 remained lower over 28 days at high HI ( $p<0.05$; Fig. 2a, b, online suppl. Table S3). The $\mathrm{pH}$ change followed a logarithmic progression at each HI (Fig. 2a), with a faster rate at high HI $(p<0.05)$. 
Table 2. Arm dryness by birthweight group over 28 days

\begin{tabular}{|c|c|c|c|c|c|c|}
\hline Mean weight and range & Day 1 & Day 3 & Day 7 & Day 14 & Day 28 & Statistics \\
\hline G1: $1,353 \mathrm{~g}(920-1,560 \mathrm{~g})$ & $0.0 \pm 0.0$ & $0.0 \pm 0.0$ & $0.0 \pm 0.0$ & $0.0 \pm 0.0$ & $0.0 \pm 0.0$ & $p=1.0$ \\
\hline G2: 2,165 g (1,570-2,450 g) & $0.02 \pm 0.03$ & $0.04 \pm 0.03$ & $0.15 \pm 0.03$ & $0.16 \pm 0.03$ & $0.02 \pm 0.03$ & $\begin{array}{l}F=6.50, p<0.001 \\
\text { Day } 7,14-S-1,3,28\end{array}$ \\
\hline G3: 2,708 g (2,460-2,990 g) & $0.00 \pm 0.02$ & $0.06 \pm 0.03$ & $0.16 \pm 0.03$ & $0.23 \pm 0.03$ & $0.02 \pm 0.03$ & $\begin{array}{l}F=13.95, p<0.001 \\
\text { Day } 14-S-1,3,28\end{array}$ \\
\hline G4: 3,237 g (3,000-4,050 g) & $0.02 \pm 0.04$ & $0.08 \pm 0.04$ & $0.08 \pm 0.04$ & $0.27 \pm 0.04$ & $0.05 \pm 0.04$ & $\begin{array}{l}F=6.75, p<0.001 \\
\text { Day } 14-S \text { - all others }\end{array}$ \\
\hline
\end{tabular}

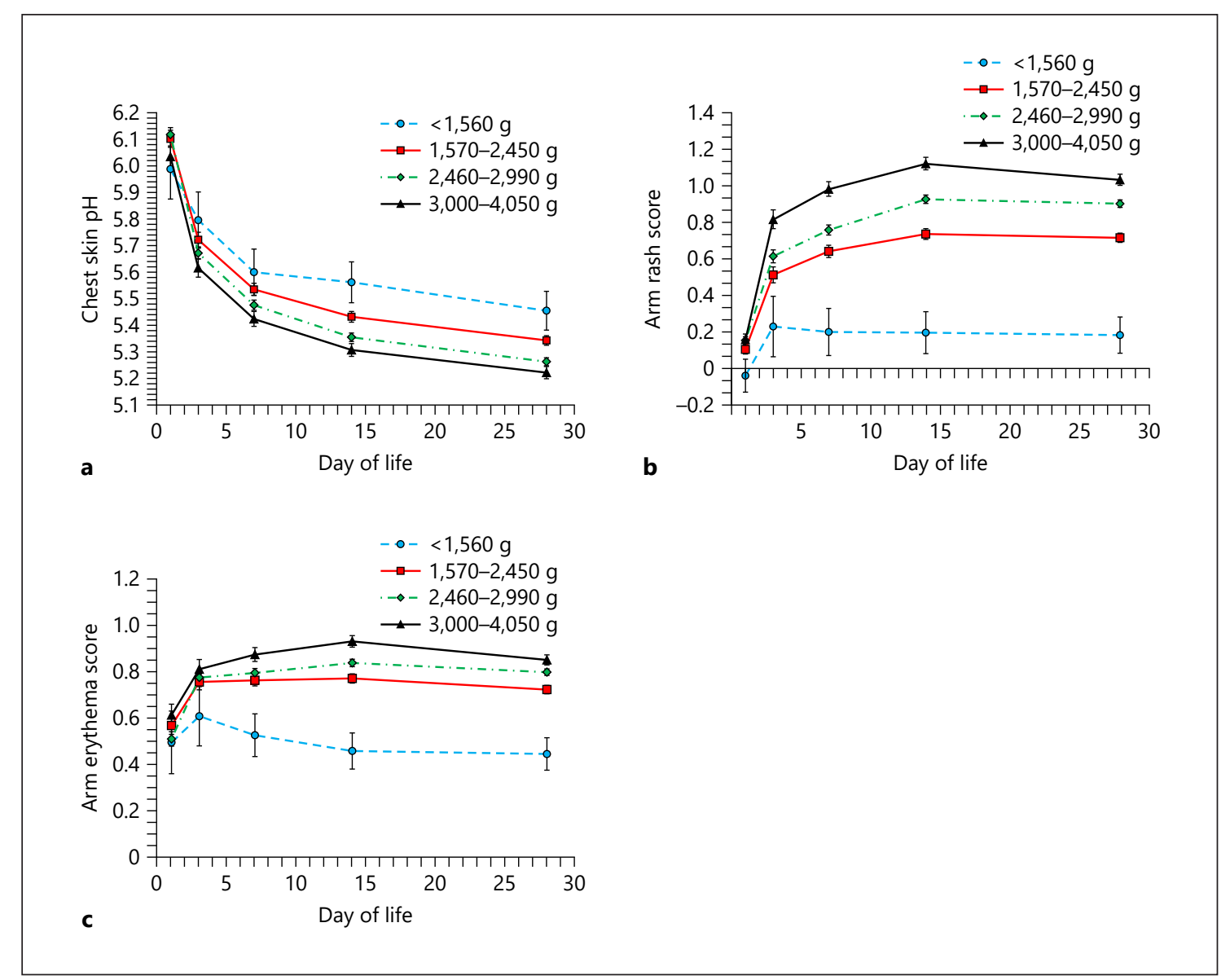

Fig. 1. Effect of birthweight group on neonatal skin integrity over time. Over 28 days, skin pH was higher for the smallest infants (920-1,560 g) than the largest infants (3,000-4,050 g) and higher for group $2(1,570-2,450 \mathrm{~g})$ than the larger groups $3(2,460-2,990 \mathrm{~g})$ and $4(3,000-4,050 \mathrm{~g} ; p<0.05 ; \mathbf{a})$. Arm and leg rash scores differed for all 4 groups versus each other $(p<0.05)$ and the smallest infants had the lowest rash levels $(\mathbf{b})$. Chest rash was of lower severity for the 2 smaller groups ( 1 and 2 ) than all other groups ( $p<0.05$; online suppl. Table S2). Erythema at all sites was lower for the smallest infants of group 1 than all others $(p<0.05 ; \mathbf{c})$. 
Table 3. Demographics by HI group as mean \pm SEM

\begin{tabular}{llll}
\hline & $\begin{array}{l}\text { Low } \mathrm{HI} \\
<34^{\circ} \mathrm{C} \text { range } \\
13.9-33.9^{\circ} \mathrm{C}\end{array}$ & $\begin{array}{l}\text { High } \mathrm{HI} \\
>34^{\circ} \mathrm{C} \text { range } \\
34.1-55.8^{\circ} \mathrm{C}\end{array}$ & Statistics \\
\hline Unique subjects & 488 & 480 & \\
Birthweight, $\mathrm{g}$ & $2,607 \pm 21$ & $2,615 \pm 21$ & $\mathrm{p}=0.72$ \\
Gestational age, weeks & $37.9 \pm 0.2$ & $37.8 \pm 0.2$ & $F=0.07, p=0.79$ \\
$\mathrm{HI},{ }^{\circ} \mathrm{C}$ & $26.3 \pm 0.2$ & $41.7 \pm 0.2$ & $F=2513.8, p<0.001$ \\
Relative humidity (\%RH) & $71.8 \pm 0.6$ & $78.1 \pm 0.6$ & $F=55.5, p<0.001$ \\
Temperature & $25.2 \pm 0.1$ & $31.4 \pm 0.1$ & $F=1059.5, p<0.001$ \\
Number of massages in $24 \mathrm{~h}$ & $3.4 \pm 0.1$ & $3.4 \pm 0.1$ & $F=0.00, p=1.0$ \\
Females/males & $219 / 269^{*}, p=0.001$ & $239 / 240, p=0.95$ & $p<0.05$ \\
Mustard oil/sunflower oil & $241 / 244, p=0.85$ & $247 / 236, p=0.48$ & $\mathrm{NS}$ \\
\hline
\end{tabular}

* Indicates gender difference.

Arm and leg erythema severities were greater at high HI starting on days 7 and 14 , respectively $(p<0.05$; Fig. 2 c, online suppl. Table S3). Rash levels were greater (arms, legs) at high $\mathrm{HI}$ every day and greater for chest on days 3, 7, 14 and 28 ( $p<0.05$; Fig. 2d, online suppl. Table S3). Dryness was greater at high $\mathrm{HI}$ starting on days 14 (arms) and 7 (legs; $p<0.05$; Fig. 2e, online suppl. Table S3).

\section{HI by Birthweight Group on Skin Integrity}

Birthweight group effects were evaluated over 28 days for each HI class individually. At high $\mathrm{HI}$, arm rash scores differed for all groups and were lowest for the smallest infants ( $p<0.05$; Fig. 3a). At low HI, arm rash severity was greater for groups 3 and 4 versus all others $(p<0.05$; Fig. 3a). At high $\mathrm{HI}$, skin $\mathrm{pH}$ was higher for group 1 than 3 and 4 and for groups 1 and 2 than 4 ( $p<0.05$; Fig. $3 \mathrm{~b})$. $\mathrm{pH}$ was higher for group 2 than 4 ( $p<0.05$; Fig. 3b). Erythema differed at high $\mathrm{HI}$ for all sites as did arm and leg erythema at low HI (data not shown). At low HI, protein varied by birthweight $(p<0.05)$, but not by pairwise comparisons.

\section{Discussion}

We examined the impact of birthweight and environmental conditions, specifically HI, on skin adaptation in a large cohort of premature and full-term neonates receiving customary repetitive daily massage with either $\mathrm{MO}$ or SSO over 28 days. The large dataset enabled determination of the effects of prematurity and high humidity/ temperature, both of global relevance with implications for neonatal innate immunity. The findings extend the knowledge from previous reports in smaller groups, more controlled settings (e.g., hospitals) and at lower temperatures/humidities.

Birthweight markedly influenced the skin's response to routine oil massage. The smallest infants had the lowest skin irritation, that is, lower erythema and rash, suggesting lower susceptibility and/or a protective mechanism against skin compromise (Fig. 1a-c). However, acid mantle development (skin $\mathrm{pH}$ decrease), was slower for infants $<1,560 \mathrm{~g}$ than the largest infants $(3,000-4,050 \mathrm{~g})$. Similarly, pH decreased more slowly for $1,570-2,450 \mathrm{~g}$ than infants $>2,460 \mathrm{~g}$.

All skin integrity measures varied significantly by $\mathrm{HI}$ class at all visits (Fig. 2a-e). Skin differences by birthweight appear to be more pronounced at higher versus lower HI. Skin $\mathrm{pH}$ was lower, starting at birth, for infants at higher HI. Given the importance of the acid mantle in skin barrier effectiveness and colonization with appropriate microflora, high HI may be protective. Yet, high HI and oil massage resulted in more skin irritation (Fig. 2c, d).

Despite the known environmental effects on skin, there are relatively few studies [14] among neonates and at high humidity/temperature. TEWL was lower at higher HI (Fig. 2b), as expected and consistent with NICU practices to reduce infant water loss. We did not measure skin hydration but anticipate that it was greater at higher HI [15]. Corneocytes take up water and structural changes occur in the keratin proteins, particularly at 85\% RH [16].

The questions are: why is neonatal skin, routinely massaged with natural oil, more irritated at higher $\mathrm{HI}$ and the skin $\mathrm{pH}$ lower? A skin $\mathrm{pH}$ reduction after birth is beneficial. An acidic $\mathrm{pH}$ enables bacterial homeostasis, colonization with appropriate bacteria and inhibition of pathogenic bacteria [17]. One potential mechanism is filaggrin 

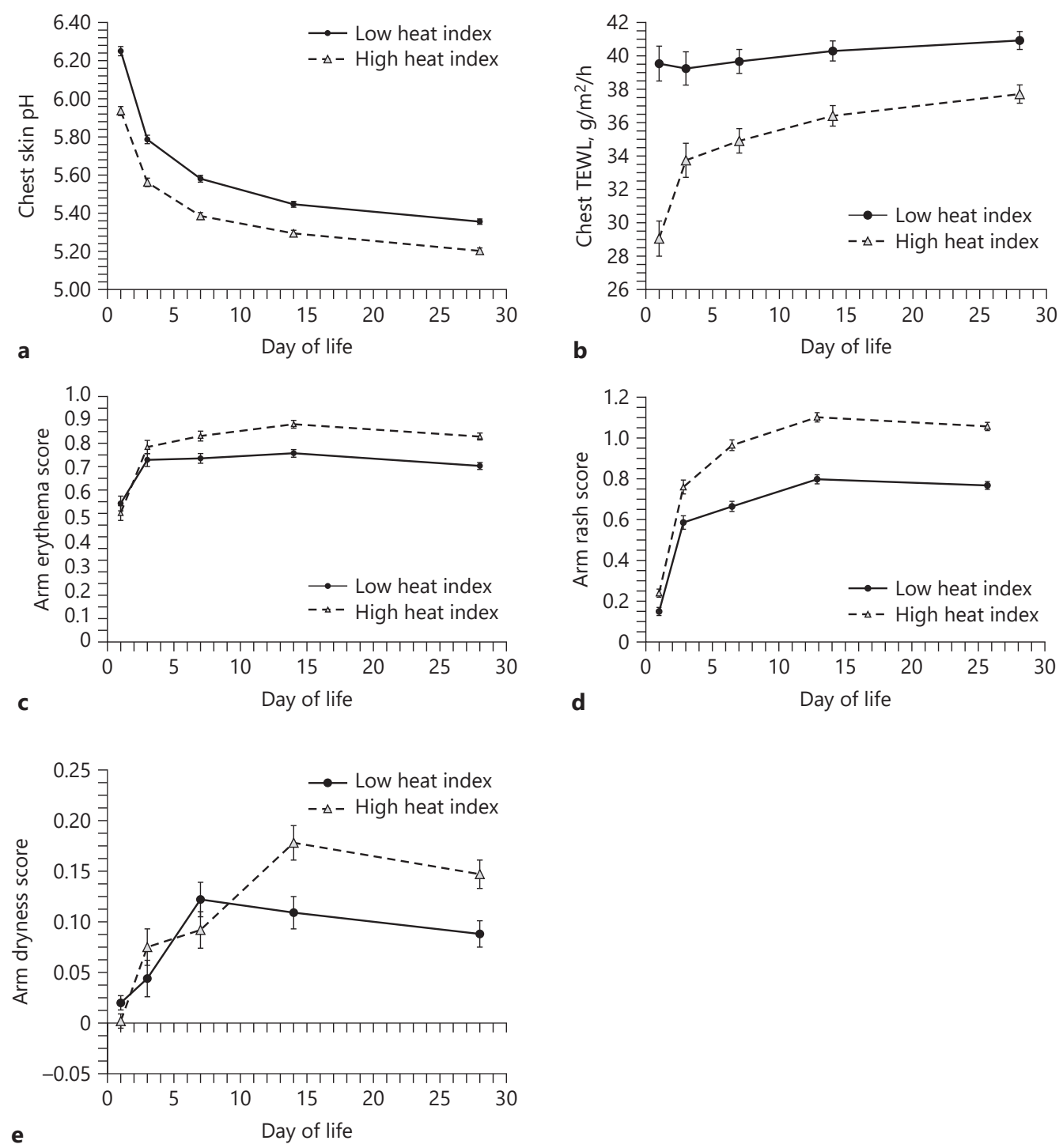

Fig. 2. Effect of HI group on neonatal skin integrity over time. At baseline, skin pH, TEWL, protein and chest erythema severities were lower and arm and leg rash severities were higher at high HI than low HI $(p<0.05)$. The lower $\mathrm{pH}$, TEWL and protein at high HI on day 1 remained lower over 28 days than did the measurements at low HI $(p<0.05 ; \mathbf{a}, \mathbf{b})$. Arm and leg erythema scores were greater at high HI beginning on days 7 and 14 , respectively $(p<0.05 ; \mathbf{c})$. Rash severities were greater for arms and legs at high HI each day and for chest skin on days 3, 7, 14 and $28(p<0.05 ; \mathbf{d})$. Dryness was greater at high HI starting on day 14 for arms and on day 7 for legs $(p<0.05 ; \mathbf{e})$.

proteolysis to produce natural moisturizing factor (NMF) [18]. Relative humidities of $80-95 \%$ were optimal for NMF formation [19], within the high HI range (Table 1). The stratum corneum absorbs water and becomes more permeable as humidity increases [20]. Fatty acids, including linoleic and oleic in these oils, enhance skin penetration in topical formulations [21]. Our higher rash and erythema at high HI may result from increased penetration of extraneous irritants on the skin.

Related to the effects of high $\mathrm{HI}$ is the finding of significant differences in rash for all 4 birthweight groups. Assuming group 1 infants were of 26-31 weeks GA, an underdeveloped skin barrier, with increased permeability and infection risk, is expected [7]. Lower rash could be 


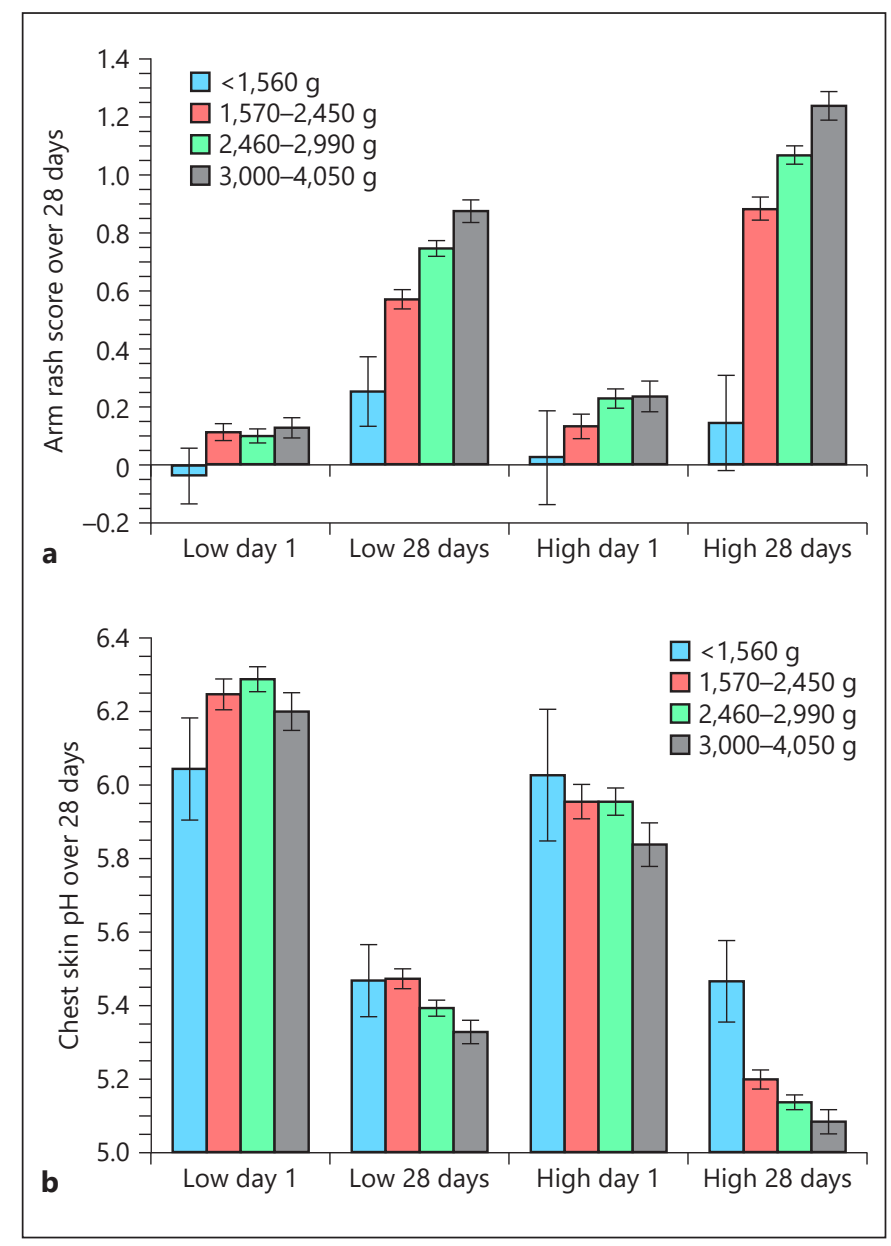

Fig. 3. Effect of HI by birthweight group. The effects of birthweight group were evaluated over the 28-day period for each HI class individually. At high $\mathrm{HI}$, arm rash differed for all birthweight groups and was lowest for the smallest infants (group $1 ; p<0.05$; a). At low HI, arm rash severity was higher for the 2 older groups 3 and 4 versus all others $(p<0.05 ; \mathbf{a})$. At high $\mathrm{HI}$, skin $\mathrm{pH}$ was higher for the smallest babies (group 1) than the 2 larger groups ( 3 and 4 ) and higher for groups 1 and 2 than $4(p<0.05$; b). At low HI, pH was higher for group 2 than group $4(p<0.05 ; \mathbf{b})$.

secondary to impaired ability to mount an inflammatory response (Fig. 1b).

Infant skin images showed miliaria to be prominent [22]. Miliaria occurs from (1) maceration by water or sweat [23]; (2) increased density of infectious microorganisms [24] and/or (3) biofilm formation [23]. Neonatal miliaria arose at high temperatures with oil application [25]. The relative absence of miliaria on day 1 may indicate eccrine gland immaturity followed by increases to day 14 as sweating develops, particularly for larger infants. Increased sweating may increase skin hydration.
Topical oils may block eccrine glands, causing water retention and miliaria.

The higher skin $\mathrm{pH}$ for the infants $<2,450 \mathrm{~g}$ (groups 1 and 2) and at lower HI may have been influenced by sweating. Sweat is an important element of skin immunity, with $\mathrm{pH}$ from 4 to 6.8 [26]. Lactic acid from eccrine glands was implicated in acid mantle formation [17]. It is possible that delayed sweating for smaller, lower GA infants contributes to the higher skin $\mathrm{pH}$ in this study. Further studies are necessary to delineate the higher $\mathrm{pH}$ in the smallest infants, given its importance in innate immunity.

Some specific features were noteworthy, as they emphasize the utility and limitations. We did not include infants who received massage without oil or topical oil without massage to elucidate the effects of birthweight and HI. This information is not relevant to this population where daily massage is the cultural norm [2]. The smallest group had only 25 subjects thereby limiting the statistical power. In this community setting, mortality is high for extremely premature infants. For simplicity, the effects of birthweight were assessed by classification rather than as a continuous variable. We did not measure hydration, creating a limitation in discerning its role. Despite segmentation into $2 \mathrm{HI}$ groups, the conditions did not encompass lower HIs found in other settings. The rates of skin barrier maturation vary with factors such as environmental exposure [27]. Therefore, the conclusions from this research pertain to the genetic, environmental, and cultural conditions of the study population, namely the Madeshi and Pahadi groups in rural Nepal. Additional studies are warranted to determine the outcomes across ethnicities, at lower temperatures/humidities, including quantitation of hydration and mechanisms of barrier damage and repair.

\section{Conclusion}

These findings suggest that high HI may be protective for low birthweight premature infants in low resource settings. They support the use of a warm, humidified incubator to facilitate acid mantle development in very low birth weight infants. Understanding the interactions between incubator temperature, humidity and skin ontogeny will likely identify strategies for optimization of skin development.

\section{Statement of Ethics}

Mothers of study subjects provided informed consent for infant participation. The Ethical Review Committee (number 247/611-E/0681069) of Tribhuvan University and the Institutional Re- 
view Board (number 000001735) of Johns Hopkins Bloomberg School of Public Health approved the study. The clinical trial was registered on ClinicalTrials.gov, NCT01177111.

\section{Conflict of Interest Statement}

The authors have no financial relationships or potential conflicts of interest to disclose.

\section{Funding Sources}

Funding was provided by the National Institute of Child Health and Development (HD060712) and the Bill \& Melinda Gates Foundation (OPP1084399).

\section{Author Contributions}

Dr. Marty Visscher made substantial contributions to design, analysis and interpretation of data; drafting the article with critical revision for important intellectual content; final approval of version to be published. Dr. Aimee Summers made substantial contributions to conception and design, acquisition of data, analysis and interpretation of data; drafting the article with critical revision for important intellectual content; final approval of version to be published. Drs. Vivek Narendran, Subarna Khatry, Jeevan Sherchand, Joanne Katz, and James Tielsch, and Mr. Steven LeClerq made substantial contributions to conception and design, acquisition of data; interpretation of data; final approval of version to be published. Dr. Luke Mullany made substantial contribution to conception and design, acquisition of data, analysis and interpretation of data; drafting the article with critical revision for important intellectual content; final approval of version to be published.

\section{References}

1 Darmstadt GL, Saha SK, Ahmed AS, Chowdhury MA, Law PA, Ahmed S, et al. Effect of topical treatment with skin barrier-enhancing emollients on nosocomial infections in preterm infants in Bangladesh: a randomised controlled trial. Lancet. 2005 Mar;365(9464):1039-45.

2 Mullany LC, Darmstadt GL, Khatry SK, Tielsch JM. Traditional massage of newborns in Nepal: implications for trials of improved practice. J Trop Pediatr. 2005 Apr;51(2):82-6.

3 Summers A, Visscher MO, Khatry SK, Sherchand JB, LeClerq SC, Katz J, et al. Impact of sunflower seed oil versus mustard seed oil on skin barrier function in newborns: a community-based, cluster-randomized trial. BMC Pediatr. 2019 Dec;19(1):512.

4 Chawanpaiboon S, Vogel JP, Moller AB, Lumbiganon P, Petzold M, Hogan D, et al. Global, regional, and national estimates of levels of preterm birth in 2014: a systematic review and modelling analysis. Lancet Glob Health. 2019 Jan;7(1):e37-46.

5 UNICEF. WHO, Bank TW, Division UNP. Levels and Trends in Child Mortality. Report 2015. In: IGME TI-aGfCMEU, editor. New York, USA: UNICEF; 2015.

6 Lawn JE, Cousens S, Zupan J; Lancet Neonatal Survival Steering Team. 4 million neonatal deaths: when? Where? Why? Lancet. 2005 Mar;365(9462):891-900.

7 Rutter N. Clinical consequences of an immature barrier. Semin Neonatol. 2000 Nov;5(4): 281-7.

8 Jehan I, Zaidi S, Rizvi S, Mobeen N, McClure EM, Munoz B, et al. Dating gestational age by last menstrual period, symphysis-fundal height, and ultrasound in urban Pakistan. Int J Gynaecol Obstet. 2010 Sep;110(3):231-4.

9 Olsen IE, Groveman SA, Lawson ML, Clark $\mathrm{RH}$, Zemel BS. New intrauterine growth curves based on United States data. Pediatrics. 2010 Feb;125(2):e214-24.
10 Odio MR, O’Connor RJ, Sarbaugh F, Baldwin $S$. Continuous topical administration of a petrolatum formulation by a novel disposable diaper. 2. Effect on skin condition. Dermatology. 2000;200(3):238-43.

11 Summers A, Visscher MO, Khatry SK, Sherchand JB, LeClerq SC, Katz J, et al. Indicators of skin barrier integrity among newborns massaged with mustard oil in rural Nepal. J Perinatol. 2018 Jan;38(1):64-70.

12 Steadman RG. The assessment of sultriness. Part I: A temperature-humidity index based on human physiology and clothing science. J Appl Meteorol. 1979;18(7):861-73.

13 Visscher M, Odio M, Taylor T, White T, Sargent S, Sluder L, et al. Skin care in the NICU patient: effects of wipes versus cloth and water on stratum corneum integrity. Neonatology. 2009;96(4):226-34.

14 Goad N, Gawkrodger DJ. Ambient humidity and the skin: the impact of air humidity in healthy and diseased states. J Eur Acad Dermatol Venereol. 2016 Aug;30(8):1285-94.

15 Cravello B, Ferri A. Relationships between skin properties and environmental parameters. Skin Res Technol. 2008 May;14(2):1806.

16 Mojumdar EH, Pham QD, Topgaard D, Sparr E. Skin hydration: interplay between molecular dynamics, structure and water uptake in the stratum corneum. Sci Rep. 2017 Nov; 7(1): 15712.

17 Fluhr JW, Kao J, Jain M, Ahn SK, Feingold KR, Elias PM. Generation of free fatty acids from phospholipids regulates stratum corneum acidification and integrity. J Invest Dermatol. $2001 \mathrm{Jul} ; 117(1)$ :44-51.

18 Elias PM. The how, why and clinical importance of stratum corneum acidification. Exp Dermatol. 2017 Nov;26(11):999-1003.

19 Scott IR, Harding CR. Filaggrin breakdown to water binding compounds during develop- ment of the rat stratum corneum is controlled by the water activity of the environment. Dev Biol. 1986 May;115(1):84-92.

20 Grice K, Sattar H, Baker H. The effect of ambient humidity on transepidermal water loss. J Invest Dermatol. 1972 Jun;58(6):343-6.

21 Kanikkannan N, Kandimalla K, Lamba SS, Singh M. Structure-activity relationship of chemical penetration enhancers in transdermal drug delivery. Curr Med Chem. 2000 Jun; 7(6):593-608.

22 Summers A, Visscher M, Narendran V, Khatry S, Sherchand J, LeClerq S, et al. Digital image analysis reveals features of neonatal skin condition after oil massage in the community setting of rural nepal. International Society for Bioengineering and Imaging of the Skin. San Diego, CA, USA; 2018.

23 Mowad CM, McGinley KJ, Foglia A, Leyden JJ. The role of extracellular polysaccharide substance produced by Staphylococcus epidermidis in miliaria. J Am Acad Dermatol. 1995 Nov;33(5 Pt 1):729-33.

24 Hölzle E, Kligman AM. The pathogenesis of miliaria rubra. Role of the resident microflora. Br J Dermatol. 1978 Aug;99(2):117-37.

25 Sardana K, Mahajan S, Sarkar R, Mendiratta V, Bhushan P, Koranne RV, et al. The spectrum of skin disease among Indian children. Pediatr Dermatol. 2009 Jan-Feb;26(1):6-13.

$26 \mathrm{Wu}$ CX, Liu ZF. Proteomic Profiling of Sweat Exosome Suggests its Involvement in Skin Immunity. J Invest Dermatol. 2018 Jan; 138(1):89-97.

27 Mack MC, Chu MR, Tierney NK, Ruvolo E Jr, Stamatas GN, Kollias N, et al. Water-Holding and Transport Properties of Skin Stratum Corneum of Infants and Toddlers Are Different from Those of Adults: Studies in Three Geographical Regions and Four Ethnic Groups. Pediatr Dermatol. 2016 May;33(3): $275-82$. 